\title{
Control of Bittercress in Florida Container Nurseries ${ }^{1}$
}

Jeffrey G. Norcini²

\section{Introduction}

Container nursery growers frequently cite bittercress as one of their more common weed problems. Not only is it a weed concern, but bittercress can harbor insect pests.

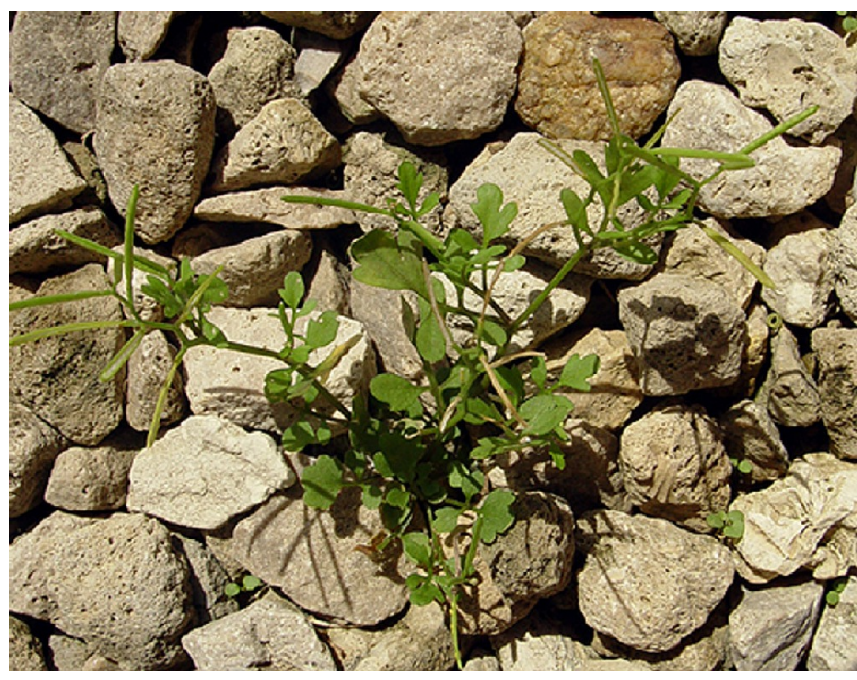

Figure 1. Hairy bittercress in a gravel bed. Credits: Melissa Thorpe

There are five species that occur in Florida, but only two are the major culprits. Hairy bittercress (Cardamine hirsuta L.) (Figure 1) is the species most associated with being a weed problem although it has been officially reported in only eight north Florida counties from Escambia to Nassau. However, hairy bittercress could find its way into nurseries statewide via plant material brought in from northern Florida and other states. It is easily confused with the more widespread Pennsylvania bittercress Cardamine pensylvanica Muhl. ex Willd. ), which occurs in $60 \%$ of Florida counties from north to south Florida. Since these species are similar and growers rarely mention which of these is a problem, it is not clear what level of threat each of these species poses to Florida growers.

It seems likely, though, Florida growers are dealing with hairy bittercress because it is a nursery weed problem in many other states, including Alabama and Georgia. Hence, the focus of this publication will be on hairy bittercress. Relevant information dealing with Pennsylvania bittercress, or bittercress species in general, will also be mentioned.

\footnotetext{
1. This document is ENH985, one of a series of the Environmental Horticulture Department, Florida Cooperative Extension Service, Institute of Food and Agricultural Sciences, University of Florida. Original publication date December 2004. Please visit the EDIS web site at http://edis.ifas.ufl.edu. 2. Associate Professor, Department of Environmental Horticulture, North Florida Research \& Education Center, Quincy, FL 32351.

The use of trade names in this publication is solely for the purpose of providing specific information. UF/IFAS does not guarantee or warranty the products named, and references to them in this publication does not signify our approval to the exclusion of other products of suitable composition. All chemicals should be used in accordance with directions on the manufacturer's label. Use pesticides safely. Read and follow directions on the manufacturer's label.
}

The Institute of Food and Agricultural Sciences (IFAS) is an Equal Employment Opportunity - Affirmative Action Employer authorized to provide research, educational information and other services only to individuals and institutions that function without regard to race, creed, color, religion, age, disability, sex, sexual orientation, marital status, national origin, political opinions or affiliations. For information on obtaining other extension publications, contact your county Cooperative Extension Service office. Florida Cooperative Extension Service / Institute of Food and Agricultural Sciences / University of Florida / Larry R. Arrington, Interim Dean 


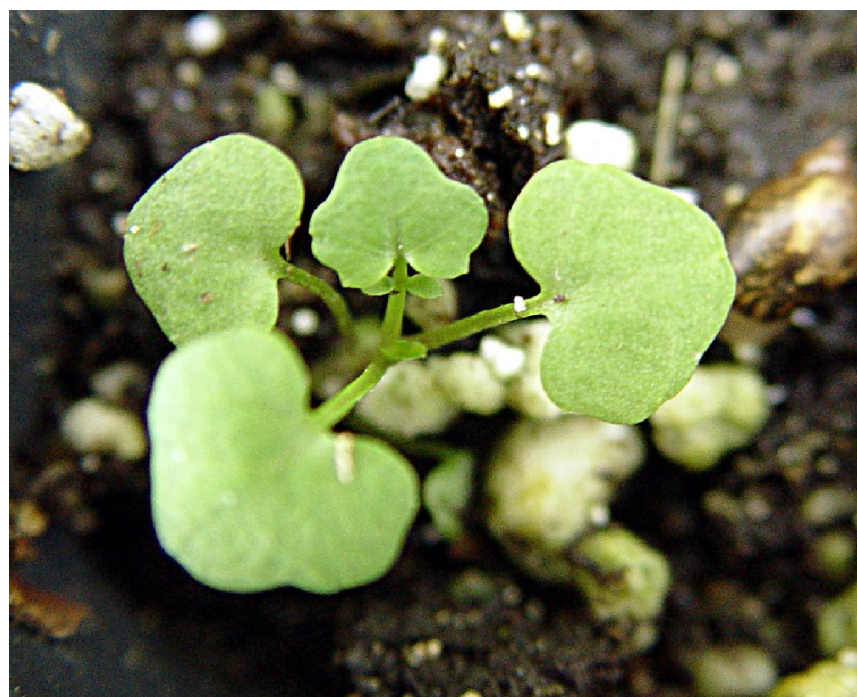

Figure 2. Leaves of hairy bittercress seedlings are distinct enough to make bittercress relatively easy to spot. Credits: Melissa Thorpe

\section{Description}

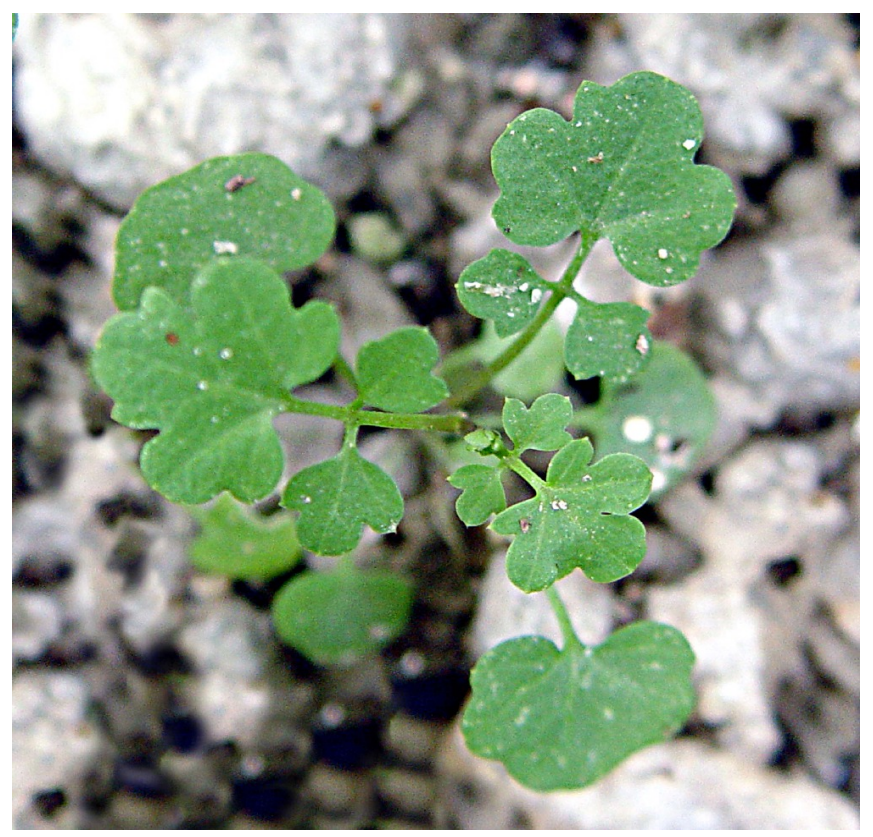

Figure 3. Hairy bittercress plants often have leaflets that are club-shaped (as in a deck of playing cards). Credits: Melissa Thorpe

Hairy bittercress is classified as a winter annual, that is, a plant that germinates in fall or winter and flowers in the spring. In Florida nurseries, it will be most prevalent during the cooler months, but it can germinate and flower any time of the year.

Leaves of seedlings are distinct enough that they can be identified when seedlings are small (Figure 2). Early detection of bittercress is important because herbicides are most effective at the seedling stage. As bittercess grows larger, leaves appear pinnately compound, with many of the lobed "leaflets" being club shaped (like on playing cards) (Figure 3).

When hairy bittercress matures, the tiny, white, four-petaled flowers will be clustered near the ends of the shoots (Figure 4). The fruit is an elongated flattened capsule called a silique (Figure 5), which is about 1 inch long. Flowers and fruit of Pennsylvania bittercress are very similar. When seed are mature, the silique bursts open and seed are ejected several feet, and even further on a windy day.

Bachman and Whitwell (1994) reported that hairy bittercress plants are capable of producing over 5000 seed, most of which can germinate within 2 weeks after being dispersed. Seed that don't land in pots or geminate can easily spread via irrigation or rain runoff, moved on the soles of workers' shoes, or they can be transported on unwashed pots.

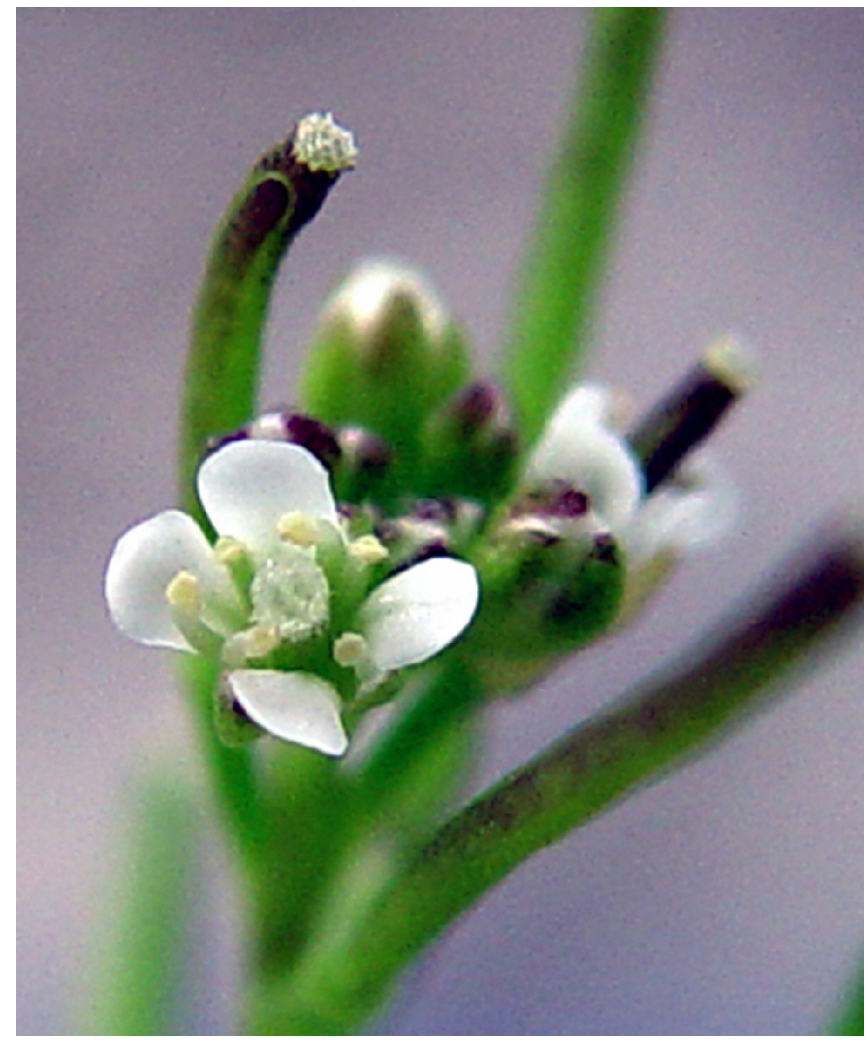

Figure 4. Closeup of a hairy bittercress flower. The tiny white flowers occur in clusters at the end of the shoots. Credits: Melissa Thorpe 


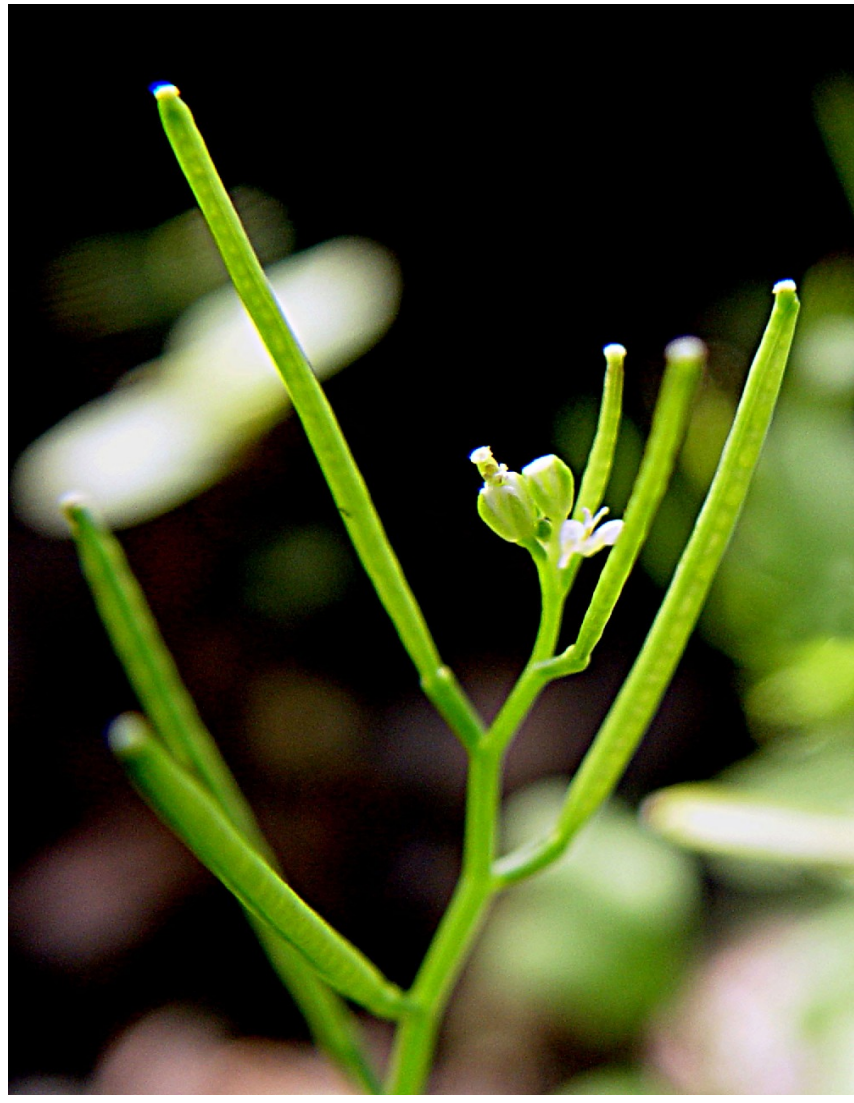

Figure 5. The elongated capsule that contains the seeds of hairy bittercress is referred to as a silique. Credits: Melissa Thorpe

\section{Control}

If bittercress is present, it is important that the species be identified. This could have an impact on control measures. Contact your local county extension agent for assistance in identifying the bittercress species. For identification purposes, it is best to submit a sample of a flowering plant.

Hairy bittercress can spread quickly in a production or propagation area since it is a prolific seed producer and the seed are readily spread as described previously. Methods to control this weed are decribed below.

Sanitation. Check for bittercress during your scouting routine for insects and diseases. Eliminate infestations on bed perimeters, in aisles, and on the perimeter of the nursery. Use a postemergence herbicide that is nonselective and translocated throughout the plant to ensure that the roots are killed. If the roots are not killed, bittercress could resprout. In general, use an herbicide that contains either glyphosate (for example, Roundup ${ }^{\circledR}$ ) or glufosinate (Finale ${ }^{\circledR}$ ) as the only active ingredient since some products contain other active ingredients not suitable for use in container nurseries. Exceptions to this rule are specially formulated products like QuikPRO $^{\mathrm{TM}}$ Herbicide (glyphosate + diquat) that are labeled for control of bittercress. For long-term control, tank mix a labeled preemergence herbicide with the postmergence herbicide. Preemergence herbicides labeled for control bittercress are listed in Table 1; however, check the postemergence and preemergence herbicide labels to determine if they can safely be tank mixed and used in your situation. Reapply a preemergence herbicide as needed according to label guidelines.

Do not mow or use a string trimmer to eliminate plants that have flowered as you probably will spread more seed. When crops are repotted or being brought into the nursery for the first time, carefully check for and remove bittercress plants and seedlings. If the bittercress in a pot has siliques, repot the plant in fresh medium that is free of weed seeds. Apply a preemergence herbicide and irrigate the plants to activate the herbicide and form a protective barrier on the medium surface.

It is also important that pots be washed. Bachman and Whitwell (1994) observed that rinsed pots had six times fewer germinating bittercress than pots that had not been rinsed off.

Preemergence control in containers. An integrated approach of sanitation plus the use of preemergence herbicides (Table 1) should prevent any significant bittercress infestations in container ornamentals. Apply these herbicides to weed-free media. The one potential exception is Gallery ${ }^{\mathrm{TM}}$ $75 \mathrm{DF}$, as noted in the following section.

Postmergence control in containers. Since there is only one postemergence herbicide labeled for bittercress control in container ornamentals, infested containers probably will have to be hand weeded. SureGuard ${ }^{\mathrm{TM}}$ is the only herbicide that will provide postemergence control in some species of conifers, deciduous trees (including some nonbearing fruit and nut species), and crape myrtles. Check the label to determine which ornamental species are tolerant of SureGuard $^{\mathrm{TM}}$. Be sure to read and follow all label 
directions. In many cases, only directed applications are specified to avoid injury.

There is some experimental evidence showing that nonflowering bittercress less than $21 / 2$ inches tall are effectively controlled by Gallery ${ }^{\mathrm{TM}} 75 \mathrm{DF}$ applied postemergence at the label rate of $1.33 \mathrm{lb}$ product per acre (Altland et al., 1999).

Conclusion. To prevent bittercress infestation utilize good exclusion and santitation practices augmented with the use of preemergence herbicides.

\section{Literature Cited}

Altland, J.E., C.H. Gilliam, and J.W. Olive. 1999. Bittercress size influences postemergence control from Gallery. Proc. Sothern Nurs. Assoc. T Res. Conf. 44:378-380.

Bachman, G. and T. Whitwell. 1994. Hairy bittercress (Cardamine hirsuta) seed production and dispersal in the propagation of landscape plants. Proc. Southern Nurs,. Assoc. Res. Conf. 39:299-302.

Table 1. Herbicides labeled for preemergent control of bittercress in container-grown nursery crops.

\begin{tabular}{|c|c|c|c|c|}
\hline \multicolumn{2}{|c|}{ Herbicide } & \multirow{2}{*}{\begin{tabular}{l}
\multicolumn{1}{c}{ Controls } \\
Bittercress \\
species in \\
general
\end{tabular}} & \multicolumn{2}{|c|}{ Only Controls } \\
\hline Trade name & $\begin{array}{l}\text { Active } \\
\text { ingredient(s) }\end{array}$ & & $\begin{array}{l}\text { Hairy } \\
\text { bittercress }\end{array}$ & $\begin{array}{l}\text { Penna. } \\
\text { bittercress }\end{array}$ \\
\hline Broadstar ${ }^{\mathrm{TM}}$ & flumioxazin & & $\mathrm{X}$ & \\
\hline Gallery'TM 75DF & isoxaben & & $X$ & \\
\hline $\mathrm{OH} 2^{\circledR}$ & $\begin{array}{l}\text { oxyfluorfen + } \\
\text { pendimethalin }\end{array}$ & & & $X$ \\
\hline PrePair $^{\circledR}$ & $\begin{array}{l}\text { napropamide + } \\
\text { oxadiazon }\end{array}$ & $x$ & & \\
\hline Regal O-O Herbicide ${ }^{\circledR}$ & $\begin{array}{l}\text { oxyfluorfen + } \\
\text { oxadiazon }\end{array}$ & & & $\mathrm{X}$ \\
\hline Ronstar $^{\circledR} 2 \mathrm{G}$ & oxadiazon & $x$ & & \\
\hline Ronstar ${ }^{\circledR} 50$ WSP & oxadiazon & $\mathrm{X}$ & & \\
\hline Rout $^{\circledR}$ & $\begin{array}{l}\text { oxyfluorfen + } \\
\text { oryzalin }\end{array}$ & & & $\mathrm{X}$ \\
\hline Snapshot $^{\mathrm{TM}} \mathrm{TG}$ & $\begin{array}{l}\text { isoxaben + } \\
\text { trifluralin }\end{array}$ & & $x$ & \\
\hline
\end{tabular}


Table 1. Herbicides labeled for preemergent control of bittercress in container-grown nursery crops.

\begin{tabular}{||l|l|l|l|l||}
\hline \hline Sureguard $^{\mathrm{TM}}$ & flumioxazin & & $\mathrm{X}$ & \\
\hline
\end{tabular}

